\title{
Repensar la nación y construir la región: visión española de los bicentenarios
} latinoamericanos

\author{
Rethinking the nation and constructing the region: \\ Latin American bicentennials, a view from Spain
}

\author{
Pedro Martínez Lillo* \\ Romané Landaeta Sepúlveda** \\ Juan Ignacio Radic Vega***
}

\section{Resumen}

Este artículo aborda desde una perspectiva continental los actuales debates existentes en América Latina a propósito de los bicentenarios, prestando especial atención a las reflexiones y cuestionamientos que se suscitan en Chile y las tensiones que se están produciendo en la región a propósito de cómo se está pensando el continente. Por tanto, la conmemoración de los bicentenarios lleva a una doble lectura: la que América Latina realiza sobre sí misma y la que lleva a España a definir su participación en la efeméride, tanto por su condición de protagonista de unos mismos hechos históricos como por su vocación iberoamericana. Estos discursos y argumentos gene-

* Profesor titular de Historia Contemporánea, UAM; <pedro.martinez@uam.es>

** Doctor (c) en Historia Contemporanea, UAM; <romane.landaeta@uam.es>

*** Doctor (c) en Historia Contemporanea, UAM; <juanignacio@fcamberes.org> 
ran visiones, proyectos y, en definitiva, políticas cuyo objetivo debería ser el contribuir a imaginar y construir el espacio latinoamericano del siglo XXI.

Palabras Claves: bicentenarios latinoamericanos, memoria, identidad(es), cultura.

\section{Abstract}

This article deals from a continental perspective with the current state of the art and debate in Latin America regarding Bicentennials, with particular focus on reflections and questions in Chile thereon. From the standpoint of the history of the present time it approaches present tensions of these festivities in the long term, generated both within the region and beyond. It also explores the traces of the Latin American identity and the various current readings.

KeY words: Latin American bicentennials, memory, identities, culture

Recibido el 16 de agosto de 2010; aceptado el 27 de septiembre de 2010 
Pedro Martínez Lillo, Romané Landaeta y J. Ignacio Radic • Repensar la nación...

\section{INTRODUCCIÓN}

La primera mitad del siglo XXI experimenta un importante acento conmemorativo en las agendas diplomáticas de las naciones latinoamericanas, debido a que se cumplen doscientos años de su independencia. Con este fin se han estado realizando innumerables iniciativas para celebrar los bicentenarios de estas repúblicas, desde aquellas más preocupadas de retocar, modernizar y renovar arquitectónicamente las obras emblemáticas de cada nación, hasta otras que han buscado la creación de numerosas comisiones y organizaciones encargadas de repasar y analizar su historia republicana. El fenómeno ha despertado variadas reflexiones considerando los cambios, permanencias y deudas presentes en muchos de estos países. En este contexto, España presenta una actitud cauta en torno a estos festejos, discurriendo en la estrategia diplomática del «acompañamiento", que tiene por objetivo que las propias naciones latinoamericanas redacten sus agendas conmemorativas transformándose en protagonistas y dejando solo en un segundo plano la actuación de España y Portugal.

En esta perspectiva, indagamos en los temas y reflexiones que están realizando sobre sí los países latinoamericanos, con especial atención a lo propuesto en Chile ${ }^{1}$. Nuestro objetivo es

1 Dos son elementos por los que utilizamos a Chile como eje de nuestras reflexiones por un lado, debido a la reiterada mención que distintos analistas realizan sobre este analizar las distintas visiones desde las cuales se está repensando el continente en el siglo XXI y los retos frente a un sistema globalizado. En ese contexto, y fruto del histórico vínculo existente, nos interesa observar el posicionamiento de la Península Ibérica ante estas celebraciones, junto a las diversas posiciones que se presentan en torno a esta estrategia. En esta línea, los bicentenarios han venido a coincidir con una política exterior de España que busca reposicionarse internacionalmente como potencia media de alcance global, esquema en el que adquieren prioridad sus relaciones iberoamericanas.

\section{LAS CONMEMORACIONES EN AMÉRICA LATINA}

\subsection{Los Bicentenarios como herramienta conceptual}

La reiterada necesidad de recordar y conmemorar diversos "pasados» ha llevado a un gran número de analistas a abordar la cuestión de los sentidos y significados de algunas fechas, las que adquieren mayor notoriedad que otras en determinados grupos sociales adscritos a una experiencia o pasado común, y que siguiendo a Maurice Halbawchs (2004), identificamos como marcos

país otorgándole un carácter ejemplar en cuanto a su trato equilibrado con la modernidad, y de otro, por los numerosos espacios creados por este país para discutir y reflexionar sobre los bicentenarios latinoamericanos. 
sociales, desde los que la sociedad civil se reconoce. Tanto ha sido el interés en el último tiempo por el «recuerdo», que Andreas Huyssen (2000:25-28) —entre otros- advierte sobre la existencia de una verdadera cultura de la memoria, que trasciende lo social para incluso llegar a lo más íntimo y particular del individuo.

Dentro de las investigaciones fundadoras que han abordado tanto la significación como la relevancia de las conmemoraciones, el trabajo de Pierre Nora (1998) instaló una impronta en el análisis histórico ya que, a propósito de los doscientos años de la Revolución Francesa, dirigió una investigación de largo esfuerzo y data, donde reflexionó junto a otros analistas los temas vinculados a la nación, la república, las identidades, las memorias y sobre todo, la significación que adquiría para Francia esta conmemoración. Ello, —advierte Nora- respondía a una dinámica histórica que solo adquiría sentido en el presente desde el que se realizaba la evocación. De otro lado y con otro acento, en Argentina, la socióloga Elizabeth Jelin (2000:1) propuso estudiar el tema de las conmemoraciones y las fechas simbólicas del pasado reciente - llamadas por la investigadora «in-felices»— a raíz de las dictaduras latinoamericanas. Ambos estudios, con preocupaciones diferentes, tienen un eje convocante que se desencadena a propósito de los hechos puntuales que se rememoran, permitiendo una reflexión desde el hoy al ayer. En ambos casos apreciamos la importancia capital que adquiere el presente en este tipo de festejos, al elaborar una narración en que existe una selección, jerarquización y reordenación constante de ese pasado al que se busca evocar, y que se hace vigente a través de rituales públicos en los que se construyen y recrean las memorias del pasado.

Dentro de las narraciones que Occidente ha elaborado para su propia comprensión de los procesos históricos ${ }^{2}$ y en el que cabe el caso América Latina, un período especialmente significativo dentro de estas conmemoraciones supranacionales es el que se refiere a la consolidación del Estado-Nación moderno (Jelin, 2003:3). Como sabemos, «las revoluciones por la independencia en Hispanoamérica fueron repentinas, violentas y universales» (Lynch, 1976:9), permitiendo la «fundación de una nueva comunidad política» (Serrano, 2009) y por tanto, convirtiéndose también en una promesa de la modernidad. En efecto, la paulatina construcción de un discurso unificador y homogéneo ha permitido dotar de coherencia a la comunidad nacional imaginada (Anderson, 1983), relegando los otros discursos a un espacio local y subalterno (Pinto, 2009:10).

En este contexto, las conmemoraciones se instalan como un fértil espacio

\footnotetext{
2 Interesante es el debate sobre la pertenencia de América Latina a un nuevo occidente. Para una visión más pormenorizada sobre el nuevo occidente ver Miguel Ángel Moratinos (2006); Felipe González (2009); Álvaro González Vargas (S/F); Vicente Palacio (2009); Marcello Carmagnani (2004).
} 
Pedro Martínez Lillo, Romané Landaeta y J. Ignacio Radic • Repensar la nación...

de análisis que permite examinar las resistencias y acuerdos de que son objeto las memorias (Da Porta, 2006), así como las identidades que cada proyecto social contiene. Así ocurrió en las celebraciones de los centenarios de las repúblicas hispanoamericanas, festejos que sirvieron de un lado para reafirmar la excepcionalidad del proyecto político moderno del Estado liberal, y de otro, para poner de manifiesto las profundas desigualdades y la compleja variedad de problemas que aquejaban a las sociedades latinoamericanas. La emergencia de este discurso crítico marcó sustancialmente la conflictividad que caracterizó al siglo XX (Lagos, 2006:124).

$\mathrm{La}$ intencionalidad, por tanto, de conmemorar un tiempo pasado se convierte en un pretexto para avalar con «esos pasados» las visiones y pretensiones que se tienen en el presente (Candina Polomer, 2000: 45-47). Dicho de otra manera, como lo expresa Marc Augé (2002:50) «son pedazos del tiempo que podemos volver a utilizar para apuntalar nuestro presente».

En este caso, las conmemoraciones bicentenarias presentan rasgos singulares, no exentos de complejidad. Son - por su carácter fundacional- actos simbólicos, nacionalistas, multidimensionales, a celebrar de manera no simultánea, dispersos en el tiempo sin una perspectiva única y continental al depender del calendario propio de cada país. En este contexto advertimos la emergencia de procesos de transformación, cambio de paradigmas, de interrogación sobre su identidad —un repensar América Latina- y divisiones que dibujan escenarios distintos, alternativos. A las crecientes diferencias políticas entre los países, el auge del populismo, la fuerza de los movimientos étnicos e indígenas y los procesos de refundación en algunos Estados, se añaden la fragmentación de los procesos de integración así como el impacto de la crisis mundial, agravando los niveles de pobreza, desigualdad y exclusión. Indudablemente, el avance de las democracias electorales y representativas que se consolidaron en los últimos veinte años no garantiza que hayan llegado a un punto de no retorno en el que los conflictos socioeconómicos se solventen dentro de los marcos institucionales y de forma pacífica.

\subsection{Temas, debates y problemáticas que se vislumbran en estos bicentenarios}

El extenso período en que se concentran los festejos de los bicentenarios latinoamericanos permite observar que estos países han situado estas fechas conmemorativas como uno de los ejes que articulan las reflexiones sobre el estado actual de la nación y su proyección futura. En palabras del ex presidente de Chile Ricardo Lagos E., «(...) reflexionar, analizar, criticar en perspectiva de lo que hemos aprendido en este siglo XX (...) [de modo que] estas conmemoraciones puedan marcar pauta de lo que será el país, o al menos, los debates que caractericen al nuevo siglo» ${ }^{3}$. En efecto,

3 Ricardo Lagos Escobar, presidente de Chile entre 2000 y 2006, ha reiterado la 
se ha insistido en abordar estas fechas como momentos «bisagra» que marcan un antes y un después en la historia latinoamericana, entendiéndolas desde un nuevo enfoque, en una perspectiva de «nueva época» que permita realizar un renovado balance de lo que ha sido cada nación, sus logros y temas pendientes, para proyectar en el futuro los desafíos particulares de los países, junto a la inserción de la región en el contexto globalizado (Garretón, 2008).

Estas ideas nos llevan a un cambio de paradigmas, a procesos de transformación y de interrogación sobre su propia identidad — «un repensar América Latina»- que dibujan escenarios distintos, alternativos. Junto a las agendas oficiales y encuentros académicos, convive otro bicentenario, el que surge con la reflexión crítica, el pensar lo latinoamericano ante el siglo XXI. Menos institucional, se esfuerza en cambio por definir y caracterizar ese tiempo. Los trabajos de Jorge Larraín, Manuel Antonio Garretón y Mauricio Tenorio resultan reveladores. Mientras el primero considera que entre

importancia de estas fechas como mecanismo de reflexión y proyección del país -y el continente- que queremos. La Comisión Bicentenario fue creada el 16 de octubre del 2002, por el Decreto Supremo $n^{\circ} 176$. Tiene por misión asesorar al presidente en la conmemoración de los 200 años de vida independiente. Desde entonces se han realizado anualmente entre los años 2003 y 2008 Foros Bicentenario organizados por el Estado, en los que han participado destacados intelectuales nacionales y extranjeros. La cita en (Lagos, 2006: 121-124). las preguntas a plantearse y responder por los propios latinoamericanos está «no solo el quiénes somos, sino, sobre todo, qué es lo que queremos ser» (Larraín, 2006), el segundo insiste en la necesidad de analizar los bicentenarios desde la perspectiva de una nueva época, es decir, en tanto que procesos y momentos de repensarse, reconstituirse y proyectarse (Garretón, 2008). La extensión de la democracia electoral se ha acompañado de desigualdades socioeconómicas, exclusiones y ausencia de dimensiones participativas. La época del bicentenario —según Garretón-llama, por tanto, a recomponer o refundar las relaciones entre el Estado y la sociedad, lo que significa un nuevo orden económico, social y político, y en la dimensión cultural, un consenso ético histórico que dé fundamento a dicho orden. Asimismo y aunque las celebraciones históricas y conmemoraciones colectivas son sobreabundantes, el historiador mexicano Mauricio Tenorio contempla el 2010 como «un buen momento para computar qué hemos aprendido, (...) una excelente excusa para echar a andar estas reflexiones». Sabiendo que toda celebración aspira a movilizar una determinada memoria, privilegiando unos acontecimientos y marginando otros al olvido, no es menos obvio que sirve —en su opinión y con una expresión igualmente irónicapara observar críticamente la imagen, o los espejismos que una sociedad elabora o viene elaborando sobre sí misma ( $\mathrm{Te}$ norio, 2010). 
Pedro Martínez Lillo, Romané Landaeta y J. Ignacio Radic • Repensar la nación...

En otro nivel, debe subrayarse la eclosión en América Latina de una comunidad epistémica definida por su naturaleza post-colonial que plantea la absoluta prioridad de descolonizar y emancipar el pensamiento, encontrar categorías de análisis vaciadas del etnocentrismo occidental que permitan replantear correctamente la problemática de los países colonizados, convencidos de que únicamente a través de esta liberación de las categorías intelectuales podrán obtenerse auténticas emancipaciones políticas, sociales o económicas. La construcción de la idea de América no puede ser aquella que reposa sobre la creación intelectual occidental, sino la generada desde un pensamiento autóctono no contaminado epistemológicamente. Los análisis de Walter Mignolo (2006) en cuanto a la fundamentación de un pensamiento «decolonial» son articulados, en una dimensión política, por otros autores que proclaman, por ejemplo, la creación de Estados plurinacionales, interculturales y postcoloniales como mecanismo de superación del Estado liberal moderno, cuya crisis considera irreversible. Y aunque aquel modelo de nuevo Estado podrá extenderse a distintos espacios, en América Latina tendrá un lugar de privilegio (De Sousa, 2007).

Un planteamiento distinto, pero muy interesante, es el que sugiere Bernardo Subercaseaux (2010). En su enfoque establece una forma, casi una metodología, para abordar —desde la perspectiva del bicentenario- la historia de las ideas y de la cultura latinoamericana tomando como referencia la categoría del tiempo histórico. En ese sentido cabría distinguir cuatro modalidades de invención colectiva en el ámbito de las nuevas naciones: «tiempo fundacional» en el que el discurso escenifica la construcción de una nación de ciudadanos alejada del pasado español; «tiempo de integración» donde el Estado, a finales del siglo XIX y principios del XX, adquiere un papel preponderante como agente de integración y armonía social; "tiempo de transformación", ante el fracaso del proyecto integrador se pretende un cambio de la estructura socioeconómica con la defensa de los conceptos de clase, revolución y anti-imperialismo, y, por último, en la actualidad, el «tiempo globalizado». Teniendo estas escenificaciones, aspectos comunes, no puede ignorarse - como destaca el autor- que existen plasmaciones locales, nacionales que, junto con otros factores, le otorgan un carácter heterogéneo y diferente. Y ahí reside una de sus riquezas, de sus complejidades.

En este contexto, identificamos varias de las problemáticas en que se han concentrado estos balances. Los análisis se han preocupado de temas asociados a las deudas pendientes del Estado moderno, especialmente aquellas vinculadas a la exclusión social y económica en que se ha mantenido a los grupos más pobres, así como al desarrollo y profundización de la democracia en el continente, junto con la consolidación de una educación preocupada por la defensa de los dere- 
chos humanos. También, y desde una perspectiva continental, las reflexiones apuntan a solucionar las brechas y paradojas que presentan en la actualidad los esfuerzos por insertar al continente en el mundo globalizado, sin perder por ello los vínculos que identifican a la sociedad con el Estado.

En materia de educación, el fenómeno de la desigualdad continúa siendo una constante que cruza estos doscientos años. Sin duda se ha avanzado, pero no lo suficiente para generar igualdad de oportunidades (Brunner: 2008, p.51 $)^{4}$. En el caso de los estudiantes universitarios en Chile, por ejemplo, deben cubrir más del $70 \%$ del coste de su educación, siendo que en España esta inversión no supera el $18 \%$, sin mencionar las profundas diferencias en cuanto a oportunidades y acceso para toda la población(Castells, 2003: 87). Las estrategias para solucionar estas diferencias han sido variadas, entre ellas, la privatización absoluta planteada desde los sectores neoliberales, hasta aquellos que insisten en una reforma al sistema educacional que reposicione al Estado como actor protagónico en el desarrollo e implementación de la educación, cuestión que ya se exponía en los debates del centenario (Letelier, 1912:687-781).

$4 \quad$ El desafío planteado por los críticos del Centenario en torno a la ampliación de la instrucción obligatoria se halla sobradamente cumplido al ver que el 99\% de los niños chilenos alcanzan los grados básicos de escolarización. Las cifras en (Brunner, 2008: 51).
En materia de desarrollo, el caso chileno resulta significativo (Aguilar Camín, 2010). Debido al recurrente carácter ejemplar con que ha sido presentado, enfatizando el avanzado nivel de democratización y sostenido crecimiento económico, que lo confirma como uno de los países más sostenibles de la región (Valenzuela, 2009). Así lo corroboran los índices macroeconómicos, que otorgan un positivo balance de los últimos veinte años en democracia, donde han disminuido considerablemente la inflación (del 27 al 4\%), el desempleo (15 al 7,5\%) y la pobreza (37 al 13\%) (Castells, 2003:84. Este sostenido crecimiento, sin embargo, se ha hecho a costa de múltiples sacrificios, fundamentalmente pagados por los sectores más pobres del país 5 . Paradojalmente, en su etapa posdictatorial, este país se ha caracterizado por presentar índices de desigualdad situados entre los más altos de la región, en el continente con mayor desigualdad del mundo 6 . El modelo chileno, denominado por algunos "sistema liberal inclusivo» (Castells, 2003) ha tendido a concebir el desarrollo como exclusiva capacidad de crecer macroeconómicamente, dejando

Esto se puede comprobar al analizar los resultado de la encuesta CASEN 2010. Incluso el exitoso gobierno de la socialista Michelle Bachelet no ha podido impedir el aumento en los índices de pobreza en el periodo 2006-2009, donde se observa 355 mil nuevos pobres. Ver encuesta CASEN, <http://www.mideplan.cl/casen/> Consultado 2-08-2010.

6 El índice GINI de 2000 señala que Chile posee un $55,9 \%$, según datos entregados por la CEPAL (Castells, 2003). 
Pedro Martínez Lillo, Romané Landaeta y J. Ignacio Radic • Repensar la nación...

de lado otros aspectos vinculados a la calidad de vida de sus ciudadanos, tal como lo plantea la lógica neoliberal de la que han sido seguidoras gran parte de las elites del continente (Larraín, 2005:69-70). Resulta sintomático observar que pese al sostenido crecimiento de Chile en los últimos veinticinco años exista un preocupante aumento de los índices de estrés y depresión que aquejan a la población en su conjunto (Salazar, 2010). Esta situación confirma que dicho modelo presenta claras y decisivas falencias. "Una sociedad reducida a la unidimensionalidad del crecimiento como forma de significado, va perdiendo sus capacidades de imaginar los contenidos reales de los debates, las utopías movilizadoras de la práctica cotidiana» (Castells, 2003). Advertimos que este tipo de deficiencias, características en el continente ha tendido a profundizar las históricas deudas que Latinoamérica tiene con los sectores más pobres de la sociedad. Al mismo tiempo, estos fenómenos se han acompañado de un creciente desarraigo social, expresado en el aumento considerable de abstención electoral (Navia, $2009)^{7}$, hecho que ha llevado a algunos analistas a plantear cuestionamientos sobre la existencia de un "nosotros», como comunidad imaginada (Subercaseaux, 2008: 153-154).

Desde esta óptica, es interesante constatar las interrogantes que surgen

Para las últimas elecciones presidenciales de diciembre de 2009 en Chile, de un total de tres millones de nuevos electores solo cien mil se inscribieron en los registros electorales. al momento de pensar sobre la identidad nacional y regional, es decir, «lo latinoamericano» si es que lo hay. Tal vez, por los mismos riesgos y matices que presenta la globalización, se tienden a relativizar los elementos que caracterizan a una nación (Lagos, 2006: 127). Son estas cuestiones, referidas a qué es lo que define realmente a la comunidad nacional y regional, lo que desde distintas ópticas se está analizando con motivo de estas conmemoraciones. Estas reflexiones son variadas: de un lado, la ya mencionada crisis identitaria de lo latinoamericano, fruto de la globalización, y de otro, el posicionamiento político que ha tenido el mundo indígena que, como sabemos, ha sido un discurso históricamente postergado, cuestiona la existencia de una comunidad nacional, al menos en los parámetros en que se ha entendido la nación a nivel oficial hasta hoy (Mignolo, 2006a). La aparición de lo que algunos denominan «indigenismo» (Malamud, 2008) interpela desde los supuestos más básicos la matriz fundacional desde la que se erigieron las distintas naciones en Latinoamérica, ya que coloca de manifiesto la alta exclusión étnica y por ende, la relativa representatividad con que se construyó el proyecto político nacional. Este propósito, mediáticamente representado por la figura del presidente de Bolivia Evo Morales Ayma y el Movimiento al Socialismo (MAS), está construyendo un modelo alternativo que junto con insertar al mundo indígena en el proyecto político nacional boliviano sustenta su poder en renovadas formas de repre- 
sentación popular, profundizando la democracia local, el co-gobierno de los sindicatos y los movimientos sociales en general, especialmente el de las comunidades indígenas. Esta nueva fórmula, en suma, pretende reformar la nación y de paso al continente, desde los propios cimientos del sistema (Gaudichaud, 2009) —es decir, el Estado_- dando un nuevo sentido al concepto de democracia directa y nación, distantes de lo que históricamente ha entendido, al menos en la praxis, el occidente tradicional sobre estos conceptos (Tapia, 2007: 307).

De forma paralela y vinculado a los gobiernos que han logrado insertarse en el mundo globalizado con una orientación reformista como han sido las agendas políticas de Brasil, Uruguay o Chile, por mencionar algunos, aun cuando reconocen las carencias con que se construyeron sus Estados nacionales y por tanto conscientes de sus históricas deudas con gran parte de su población, consideran estas conmemoraciones como un momento propicio para reformular — moderadamente, eso sí- el proyecto político moderno. Se consideran fundamentales las relaciones entre el Estado y la sociedad con el fin de alcanzar en el nuevo siglo un continente más integrado e inclusivo, insertando estas nuevas estrategias de refundación de occidente donde se incluya a América como parte fundamental. Alcanzando por tanto un consenso ético que contenga la pluralidad no solo étnica sino también cultural, se podrá dar fundamento durante el siglo XXI a un nuevo orden (Garretón, 2008:2).
En esta línea se inscribe el gobierno de Luis Inacio Lula da Silva en Brasil. Desde sus inicios ha elaborado una política social, conocido como Programa Bolsa de Família, encargada de compensar las enormes desigualdades económicas existentes en el país, aun cuando sus detractores insisten en concebirlas como medidas asistencialistas dentro de una política neoliberal, que no impulsan verdaderamente un desarrollo de los sectores más pobres de la sociedad (Márquez y Méndes, 2010). No obstante y pese a la sostenida crítica al gobierno de Lula por parte de los diversos sectores de la izquierda brasileña, entre los que se cuenta el Movimiento de los sin Tierra (MST) y pese a las nefastas consecuencias que estas políticas provocan en la clase trabajadora, no dejan de reconocer en él un intermediario válido para dirigir los destinos de la nación, al respetar las instituciones democráticas y no criminalizar a estos movimientos sociales a quienes contempla, incluso como actores válidos en el diálogo social (Sánchez y otros, 2008: 104).

Por tanto, se reconoce la existencia de lazos vinculantes entre los distintos miembros de la sociedad que permiten hablar de una historia común con la existencia de un proyecto latente incluso en los excluidos históricos del sistema (pobres, indígenas, mujeres) pero constantemente dispuestos a su inserción en esta matriz común. Se establece un reconocimiento del pasado común que caracteriza y vincula a los miembros de las naciones latinoameri- 
Pedro Martínez Lillo, Romané Landaeta y J. Ignacio Radic • Repensar la nación...

canas (Serrano, 2003). Ese pasado, pese a las enormes deudas existentes, permite dar coherencia al nuevo discurso que busca reconstruir a estas sociedades, ahora desde nuevos fundamentos, sin que ello implique necesariamente un quiebre con el sistema imperante.

La producción intelectual que acompaña estas conmemoraciones, aun cuando se diferencia en sus propuestas, tiende a constituirse como discurso que aglutina a la región. Existiendo una exaltación de lo nacional que caracteriza a este tipo de festividades, cabe plantear la validez de aquellas que exponen su escepticismo al analizar a la región en general y este tipo de celebraciones en particular como una sola unidad (Malamud, 2008: 5).

En cambio, otros posicionamientos reafirman la prudencia de ver en estos festejos la oportunidad de repensar el continente destacando los elementos aglutinantes que dotan de un carácter común, intrínsecamente latinoamericano creador de una conciencia propia (Larraín, 2006:166). En esta perspectiva, la opción de repensar la comunidad nacional desde la diversidad, a partir de la formación de las identidades con un enfoque integrador, se torna fundamental frente al desarrollo de las potencialidades del continente en sus desafíos ante el nuevo centenario que se ha iniciado y a las posibilidades ciertas de proyectar su inserción en el sistema internacional como parte de un nuevo proyecto político occidental. En esta línea, las propuestas que se están barajando en Europa en general y en
España en particular, resultan congruentes frente a la idea de entender al continente americano como elemento fundamental en la reformulación del proyecto político occidental.

\section{ESPAÑA Y LOS BICENTENARIOS LATINOAMERICANOS}

\subsection{Estrategia diplomática española} frente a los bicentenarios

Los bicentenarios han venido a coincidir con una política exterior de España que busca reposicionarse internacionalmente como potencia media de alcance global, esquema en el que adquieren prioridad sus relaciones iberoamericanas. Ese reconocimiento, «Iberoamérica es el continente del futuro» en palabras de Zapatero (2008:19), no puede ocultar, sin embargo, factores y tensiones que subyacen a la hora de su elaboración y ejecución.

La economización de la acción exterior en la etapa Aznar, espejo de la masiva presencia empresarial en América Latina, generó profundas disfunciones en torno a la imagen de España — «izarro capitalista»—, así como críticas por su responsabilidad en el deterioro de las condiciones sociales de la región, denuncias que se acentuaron con la deriva a la izquierda de algunos gobiernos pero, sobre todo, de movimientos sociales y políticos cuyos discursos se legitiman con el rechazo 
del neocolonialismo ejercido por las empresas españolas. Para «reparar daños», Zapatero priorizó un giro social en la acción latinoamericana (cohesión social, ayuda al desarrollo, responsabilidad social empresarial) dentro de una política exterior comprometida (multilateralismo, solidaridad), aproximó discursos ante la pluralidad políticocultural y empleó el "poder blando» en el caso de la diplomacia pública (Barbé, 2009: 131-143). Si a finales de los años noventa la irrupción de las empresas españolas provocaba un clima de opinión hostil, a principios del siglo XXI la imagen de España mejoraba sustancialmente (Noya, 2009: 99-102).

Otros componentes de la estrategia española siguen mostrando fragilidades. La idea de Comunidad Iberoamericana, forjada en la transición, organizada en torno a las Cumbres Iberoamericanas y cuya legitimidad descansa en el factor democrático además de los valores compartidos, necesita revisarse para generar nuevas retóricas. Su discurso integrador encuentra clara falta de sintonía y conflictos en el sentimiento de pertenencia a una "patria compartida", frente a realidades que incluyen desde el impacto de la inmigración, la diversidad cultural y lingüística, la pobreza y la heterogeneidad estructural hasta el indigenismo y sus cosmovisiones o la emergencia de potencias globales en América Latina. Similar reflexión cabría realizar ante la continua pérdida de interés de la opinión pública española hacia lo latinoamericano, en contraste con la atención que suscitan los espacios europeos y norteamericanos ${ }^{8}$. Indica Esther Barbé «el nosotros — comunidad política asentada en valores- se asocia a Europa y no al espacio iberoamericano» (Barbé, 2009: 127-128). Asimismo, el encontronazo entre el Presidente de Venezuela y el Rey de España, en la Cumbre Iberoamericana de Santiago de Chile, constituye un símbolo mediático de la «fragilidad comunitaria» (Barbé 2009).

Replantear ese sentimiento de pertenencia en torno a nuevas bases, más abiertas a la ciudadanía, a sus problemáticas, y menos a las élites, construyendo estrategias frente a problemas comunes, educación, desarrollo, desigualdad, sostenibilidad ambiental, perfeccionamiento del Estado de derecho, en el modelo de una sociedad del bienestar se apuntan en el horizonte como alternativas (Noya, 2009: 503-504). En otro orden, España sigue enfrentando el reto de superar la contradicción permanente visible en los siglos XIX y XX entre un discurso gubernamental que reafirmaba la prioridad de América Latina en sus políticas exteriores y una realidad que, con matices según la época, lo niega, para acabar imponiendo la opción de utilizar América en apoyo de sus intereses propios, alejándose de la horizontalidad en las relaciones (Pérez Herrero, 2003: 328-339).

\footnotetext{
8 Fundación Carolina, Barómetro (2008) América Latina y la cooperación al desarrollo en la opinión pública española, p. 5; América Latina y la cooperación al desarrollo en la opinión pública española, Madrid, p. 5.
} 
Pedro Martínez Lillo, Romané Landaeta y J. Ignacio Radic • Repensar la nación...

La posición oficial española arrancaba en mayo de 2007 con la creación, por Real Decreto 595/2007, de la Comisión Nacional para la Conmemoración de los Bicentenarios de las Independencias de las Repúblicas Iberoamericanas adscrita a la Vicepresidencia Primera del Gobierno-, a cuyo frente estaría el ex presidente Felipe González, una designación que respondía a su conocimiento de la región, a la necesidad de hacer más eficaz el proyecto, disipar malentendidos, amortiguar críticas y, sin duda, al hecho de que sus propuestas actuales diseñan una política, casi una hoja de ruta para el siglo XXI iberoamericano (González, 2009). Entre sus cometidos destacaban los de fijar líneas de colaboración y trabajo coordinado con similares comisiones bicentenarias de los países latinoamericanos. Dos años después, el 11 de mayo de 2009, quedaba solemnizado en un gran acto institucional en Casa de América, bajo la presidencia de los Reyes, la incorporación de España a las celebraciones. «Acompañamiento y sabia prudencia» a saber, una presencia de perfil menor conformaba la clave del discurso oficialista. España se limitaría a acompañar en los actos que estas naciones decidieran, sin reclamar liderazgo alguno. Estar en el recordatorio de ese tiempo común, con el fin de colaborar, ayudar, integrar, pero sin dar pie a figurar en el «banquillo de los acusados». La agenda oficial española concluía en sus discursos, contagiada de triunfalismo, «ha llegado la hora de Iberoamérica»; exponente de su capacidad democrá- tica, de una mayor participación en la gobernanza global y su incorporación a un «Nuevo Occidente».

En el fondo, pocas novedades. O muy poco que hiciera presumir cambios o modificaciones en la retórica diplomática convencional. No obstante, en su acción exterior latinoamericana, los bicentenarios se presentan como la ocasión para profundizar en una relación que es "constitutiva del corazón mismo de nuestra personalidad ${ }^{9}$. Noción de comunidad, pertenencia, identidad que el presidente español José Luis Rodríguez Zapatero reforzaba al entender que «la mitad de nuestro ser se ha forjado en América» (Zapatero, 2008:18).

\subsection{España, América Latina y el Nuevo Occidente. Una visión estratégica}

Si el «acompañamiento y la sabia prudencia» marcan discursos y comportamientos oficiales, la estrategia viene definida por un proyecto que nos remite a la forma en la que España, en su deseo de potencia media global, contempla la inserción de América Latina en el sistema internacional del siglo XXI, la nueva era global y su contribución a la gobernanza mundial.

9 Real Decreto 595/2007, (4-V-2007), вОЕ $\mathrm{N}^{\mathrm{o}}$ 113, (11-V-2007), p. 20314; Real Decreto 1074/ 2007, (31-VII-2007), BOE N ${ }^{\circ}$ 183, (1-VIII- 2007); Real Decreto 1258/ 2007, (21-IX-2007), BOE No 230, (25-IX2007). 
El nuevo protagonismo latinoamericano - en la óptica española- se vincula en torno al paradigma del «Nuevo Occidente», imagen entendida por su naturaleza instrumental (organización del poder mundial), valórica (factor de legitimación en las relaciones internacionales) y cultural e identitaria (Moratinos, 2006:82). Por un lado, apunta a la creación de un gran espacio atlántico, rediseñando las relaciones transatlánticas, conformado por el triángulo - trípode- Norteamérica (Estados Unidos y Canadá), Unión Europea y América Latina. Generadora del 62\% del Producto Interior Mundial, incluyendo casi un tercio de los Estados del mundo, espacio de intensos flujos migratorios, mecanismo de concertación frente a los grandes desafíos del tiempo presente (terrorismo, lucha contra la pobreza o protección ambiental) y defensor de la multilateralidad, el «Nuevo Occidente» se configura sobre la revisión crítica junto al reacomodo del concepto occidental, refundándolo (De la Puerta, 2009: 128-129). Sus viejos paradigmas no valen, aparecen como caducos y superados por el reconocimiento de errores y fracasos. Su base, en cambio, son los que conservan intacta toda su capacidad para inspirar y movilizar personas y países: libertad, igualdad, respeto, tolerancia (Palacio, 2009).

El «Nuevo Occidente», así concebido, estructura no una geografía física (Europa o Estados Unidos) sino una comunidad de valores, abierta a quienes los comparten. Y entre esos actores, para el ministro de Asuntos Exteriores y
Cooperación, Miguel Ángel Moratinos, América Latina se convierte en una plataforma democrática. Sus repúblicas, sostiene:

[...] nacidas bajo el poderoso influjo de los vientos de la libertad que soplaban desde París, Filadelfia o Cádiz son en la actualidad uno de los continentes más democráticos y donde - a pesar de las dificultades derivadas de la desigualdad social- la mayoría de sus ciudadanos sigue plenamente comprometida con la defensa y la promoción de las libertades (Moratinos: 2006).

Sin América Latina no hay un nuevo proyecto occidental, insiste el ministro. Su presencia en el triángulo Atlántico, además, reequilibra la relación anglosajona-latina (en 2025 los 1.000 millones de hispanos y portugueses será una de sus aportaciones a la gobernanza mundial) y permite «resituar» el valor de lo anglosajón. "Todo lo que era anglosajón, a su juicio, tenía la vitola de la perfección, de la legitimidad, de la absoluta seguridad. Sin embargo, a lo largo de las últimas décadas esa actuación anglosajona no ha sido para sentirse extremadamente orgulloso de ese Occidente que queremos compartir» (Moratinos, 2006). La presidencia española de la Unión Europea, enero/ julio 2010, apuntó a la concertación del denominado «trípode occidental» aunque el proyecto careció de concreción al no existir respuesta de las partes involucradas (De la Iglesia, 2009:10). Las dudas surgen al observar las sombras que suscita entre los actores de la 
región el apellido "occidental». Más aún cuando asistimos a la emergencia de potencias, como el caso de Brasil, que presentan diversos intereses y orientaciones múltiples. «¿Quiere América Latina pertenecer a Occidente?» se preguntaba Carlos Mesa, ex presidente de Bolivia, al analizar la deriva política de algunos países (Basteiner, 2009).

Seguramente, un componente menos ideológico, más pragmático, gozaría de un mayor consenso para un camino común entre España y América sin sacrificar principios (El País, 2009). En esas coordenadas sitúa sus discursos Felipe González. Los avances democráticos y la existencia de un capital humano de mismo trasfondo cultural y vínculos permiten una comunidad iberoamericana ambiciosa. Punto vital de esta propuesta es la educación y la formación. «El gran reto es que la generación del bicentenario sea la mejor preparada de la historia» (González 2009A: 4-5). Y junto al capital humano, las reformas estructurales aún pendientes sin las cuales resultará imposible aquella inserción en la dinámica global.

En cualquier caso, queda la impresión de que el tiempo del bicentenario se asimila, como reto desde las visiones españolas, a la construcción de una nueva modernidad occidental que integre a esta región, con capacidad para insertarla en el mundo global del siglo XXI y como elemento superador de insuficiencias, fragilidades y limitaciones pasadas, promoviendo en cambio desarrollo, cohesión social y democracias respetuosas ante lo plural y lo diverso. Si la modernidad política nacía del reconocimiento de la libertad, la del presente siglo parece hacerlo asumiendo la necesidad de articular espacios sociales de integración e inclusión, garantizando calidad de vida a sus ciudadanos, a sus derechos y aspiraciones, en todos sus aspectos y direcciones. Esta modernidad necesita, como lo requirió hace 200 años, la palabra y la obra, la presencia y la participación, en libertad, con libertades, de la ciudadanía latinoamericana. Ese es el requisito imprescindible.

\section{REFLEXiOneS FinALES}

La reflexión iberoamericana conforma un elemento permanente en la dinámica española. Afrontarlo en el tiempo de los bicentenarios le otorga, además, valor añadido. Ya sea por su naturaleza de conmemoración histórica, que nos afecta, como por coincidir la región con especiales realidades sociales, políticas, culturales y económicas y, en el marco de una nueva era global, el desafío intelectual resulta formidable. Seguramente, más allá de los actos oficiales y de la estrategia del acompañamiento, una de las potencialidades de los bicentenarios descansa en su capacidad para reflexionar en común y sin ignorar su complejidad sobre pasado, presente y futuro. Y en diferentes planos. De un lado, la revisión de una historia compartida que apunta al nacimiento de la modernidad política. De otro, los grandes desafíos del tiempo actual, 
desde la gobernanza democrática hasta el reconocimiento de las pluralidades étnicas y culturales. Igualmente, el impulso de las relaciones entre España y América Latina, así como el marco en el que se desarrollarán y los factores de legitimidad sobre los cuales apoyar la acción exterior española en América. Repensar, en definitiva, una comunidad iberoamericana que contemple al ciudadano en el marco de sociedades de bienestar, con soluciones a los problemas derivados, entre otros, de la inmigración o la desigualdad, con horizontalidad en las relaciones y compromisos recíprocos entre los pueblos. Bajo esas consideraciones y con la capacidad de su poder blando y de diplomacia pública, la política española en América incrementará sus opciones y, con ello, su objetivo de potencia media global.

Esa misma dinámica sirve para suscitar la incorporación del mundo latinoamericano al sistema internacional de la nueva era global. Políticamente, la lógica y las prácticas democráticas que vertebran la región empujan su presencia en un «Nuevo Occidente, una modernidad en constante evolución, sin fronteras", articulando un gran espacio atlántico junto a la Unión Europea y Norteamérica. Sin tanta carga ideológica, más pragmático, un segundo esquema de inserción sitúa un mundo iberoamericano para el siglo XXI a partir de un modelo reformista, fruto de un nuevo pacto mercado y Estado, con crecimiento y redistribución de los ingresos, calidad democrática y Estado eficiente, con un esfuerzo en educa- ción, formación y salud, superador de la pobreza y la exclusión. Sea en un mecanismo u otro, queda la impresión de un espacio - diverso, plural, transformándose - al que desea verse aferrado a unos paradigmas atractivos pero, quizá, en exceso rígidos.

Del lado latinoamericano, la celebración de los doscientos años de la independencia, plantea una oportunidad única para analizar y reflexionar sobre los supuestos, ideas y valores desde los que se está pensando la nación en particular y América Latina en general en el siglo XXI, realizando lecturas comunes que llevan a una discusión compartida, reclamando un debate histórico.

Algunas de las propuestas que se están construyendo en la esfera occidental, y en las que destaca la que presenta la diplomacia española, llaman a realizar un giro social en las relaciones con Latinoamérica. Este discurso integrador que rescata la imagen de tener una patria compartida, considera reformular las bases sobre las cuales reconstruir el «nosotros» iberoamericano desde nuevos paradigmas que inserten en un estatus igualitario al continente americano en las relaciones de poder con el occidente tradicional. Esta política, denominada «Nuevo Occidente», ciertamente converge con los propósitos y lineamientos que algunos gobiernos de la región que vislumbran como el objetivo a conseguir: superando las históricas deudas pendientes, mediante la creación de un Estado de bienestar, posicionándose como un actor integrado y protagónico en el sistema internacional. 
Pedro Martínez Lillo, Romané Landaeta y J. Ignacio Radic • Repensar la nación...

Las dudas surgen al observar la fuerza con que han emergido en el último tiempo proyectos políticos alternativos, que rescatan el discurso subalterno de marcada posición anticolonial. Pero, ¿está dispuesta América Latina a superar los temas pendientes e insertarse con toda su compleja pero rica diversidad étnica y cultural en este nuevo proyecto de civilización? Por su parte, cabe preguntarse cuáles serán los mecanismos con los que Occidente incitará al continente americano a superar la difícil y traumática imagen que las antiguas metrópolis han despertado para gran parte de su población. La pregunta ya está sugerida. Su respuesta, la debemos esperar, observando este proceso que está en curso. Sin embargo, planteamos nuestro escepticismo en torno a si estas conmemoraciones realmente ofrecen una oportunidad para proyectar al continente como una unidad política y cultural, debido a que, fundamentalmente, estas celebraciones presentan un marcado y exclusivo carácter nacional. Mientras, los bicentenarios se nos presentan como una útil herramienta analítica que permiten reconocer cómo se está pensando el continente en el siglo XXI.

\section{REFERENCIAS BIBLIOGRÁFICAS}

Aguilar Camín, Héctor (2010), «Aguilar Camín frente al Bicentenario", en El Mercurio, (27-02-2010). <http://edicion2702. blogspot.com/2010/04/aguilar-caminfrente-al-bicentenario.html> Consultado el 8 de agosto de 2010 .
Anderson, Benedict (1983), Comunidades imaginadas. Reflexiones sobre el origen y la difusión del nacionalismo, México D. F., Fondo de Cultura Económica, 2007 (4 ${ }^{\circ}$ reimp.), $1^{\circ}$ ed. en inglés, 1983.

Augé, Marc (2002), Diario de Guerra. El mundo después del 11 de septiembre, Madrid, Gedisa, p. 50.

BARbÉ, Esther (2009), «Tensiones de la política exterior española hacia América Latina: comunidad, imagen y liderazgo", en Arenal, Celestino (coord.), España y América Latina 200 años después de la Independencia. Valoraciones y perspectivas, Madrid, Marcial Pons-Real Instituto Elcano, pp. 127-128 y 131-143.

Bastenier, Miguel Ángel (2009), «El estropicio de la modernización», en El País (7 de octubre de 2009).

Brunner, José Joaquín (2008), «Los debates de la República educacional: 1910 y 2010», en Figueroa, Maximiliano y Manuel, Vicuña; El Chile del Bicentenario, Santiago, Ed., Diego Portales, p. 51.

Candina Polomer, Azún (2000), «El día interminable: memoria e instalación del 11 de septiembre de 1973 en Chile (19741999)», en Jelin, Elizabeth (2000), Las conmemoraciones: Las disputas en las conmemoraciones in-felices, Madrid, Siglo XXI, pp. 45-47.

Carmagnani, Marcello (2004), El otro Occidente: América Latina desde la invasión europea hasta la globalización, México, El Colegio de México.

Castells, Manuel (2003), «El modelo democrático chileno de desarrollo", en Foro Bicentenario; Chile Hoy: ¿Acercándonos al umbral del desarrollo?, en Santiago, Foro Bicentenario, Presidencia de la República, p. 87.

DA Porta, Eva (2006), «Conmemoraciones del pasado reciente en Argentina», en Astrolabio $n^{\circ} 1$, Revista virtual Centro de Estudios Avanzados de la Universidad de Córdoba, Córdoba 2006. <http://www. scribd.com/doc/19823847/conmemoraciones-mediaticas-del-pasado-reciente- 
en-argentina $>$ Consultado el 19 de marzo de 2010.

De La Iglesia, Juan Pablo (2009), «Presentación de las orientaciones de la Presidencia Española de la Unión Europea», en X Foro de Biarritz, (Quito, 1 y 2 de octubre de 2009), Boletín Fundación Carolina, $n^{\circ}$ 18, diciembre, p. 10.

De La Puerta, Javier (2009), «Lecciones de la Segunda Guerra Mundial», en Política Exterior $\mathrm{n}^{\circ} 132$, noviembre-diciembre, pp. 148-149.

De Sousa Santos, Boaventura (2007), «La reinvención del Estado y el Estado plurinacional», en OSLA n ${ }^{\circ} 22$ (año VIII), septiembre.

Diario El País (2009), «El Nuevo Occidente», en Editorial, El País, 17 de mayo.

Garretón, Manuel Antonio (2008), «Bicentenarios: tiempos de repensar la región», en Diario El Clarín Electrónico, 20 de enero. Consultado el 25 de noviembre de 2009.

Gaudichaud, Frank (2009), "América Latina entra en una nueva fase», en Rebelión, (28-VIII-2009). <http://www.rebelion. org/noticias/2009/9/92317.pdf> Consultado el 9 de abril de 2010.

GonZÁlez, Felipe (eds.) (2009), Iberoamérica 2020. Retos ante la crisis, Madrid, Editorial Siglo XXI-Fundación Carolina. (2009A), «¿Qué podemos hacer?", en Miradas al Exterior. Revista de Información Diplomática, Madrid, Ministerio de Asuntos Exteriores y Cooperación, $\mathrm{n}^{\mathrm{o}}$ 10, abril-junio, pp. 4-5.

GonZÁlez VArgas, Álvaro (S/F), «El Nuevo Occidente y la redefinición de la política exterior de Costa Rica", en Revista Ixchel Vol. I, Sin fecha. <http://www. revistaixchel.org/volumen-i/geoploiticaliteratura/70-el-nuevo-occidente-y-laredefinicion-de-la-politica-exterior-decosta-rica.html>

Halbawchs, Maurice (2004), Los marcos sociales de la memoria, Madrid, Ed. Anthropos.

Pérez Herrero, Pedro (2003), «Las relaciones de España con América Latina durante los siglos XIX y XX. Discursos gubernamentales y realidades», en Pereira, Juan Carlos (coord.), La política exterior de España (1800-2003), Barcelona, Ariel, pp. 328-339.

Huyssen, Andreas (2000), «El Parque de la memoria: una glosa desde lejos», en Punto de vista $n^{\circ} 68$, año XXIII, Buenos Aires, p. 25-28.

Jelin, Elizabeth (2000), Las conmemoraciones: Las disputas en las conmemoraciones in-felices, Madrid, Siglo XXI, p. 1.

Lagos, Ricardo (2006), "Discurso de Inauguración del Foro Bicentenario 2004", en América Latina mira al Bicentenario: Desafíos de la Democracia, Cultura y las identidades, Foro Bicentenario, Santiago, Comisión Bicentenario, p. 124.

LARraín, Jorge (2006), "Hacia un bicentenario globalizado: ¿identidad nacional o identidad latinoamericana?», en Foro Bicentenario 2004, Santiago de Chile, Presidencia de la República, 2006.

(2005), ¿América Latina moderna? Globalización e identidad. Santiago, LOM ediciones, pp. 69-70.

Letelier, Valentín (1912), Filosofía de la Educación. Santiago de Chile y Buenos Aires, Ed. Juan Nascimento y Cabut, pp. 687-781.

LYNCH, John (1976), Las revoluciones hispanoamericanas 1808-1826, Barcelona, Editorial Ariel, p. 9.

Malamud, Carlos (2008), "Los riesgos de España frente a los bicentenarios: populismos, nacionalismo e indigenismos", en Real Instituto Elcano, Madrid, 2008. <http://www.realinstitutoelcano.org/wps/ portal/rielcano/contenido?WCM_GLOBAL_CONTEXT=/elcano/elcano_es/ zonas_es/america+latina/dt34-2008> Consultado el 30 de marzo de 2010.

Márquez, Rosa y Áquilas, Méndes (2006), "O social no governo Lula: a construção de um novo populismo em termos de aplicação de uma agenda neoliberal», en Revista de economía, Vol. 26, n ${ }^{\circ}$, JanMar - 2006, Brasil, pp. 58-74. <http:// 
Pedro Martínez Lillo, Romané Landaeta y J. Ignacio Radic • Repensar la nación...

www.rep.org.br/pdf/101-4.pdf> Consultado el 12 de abril de 2010.

Mignolo, Walter (2006), La idea de América Latina. La herida colonial y la opción decolonial, Barcelona, Gedisa.

(2006a), «¿Giro a la iz-

quierda o giro decolonial? Evo Morales en Bolivia", en Revista del Sur, marzo-abril 2006. <http://waltermignolo. com/2006/11/19/\% C2\%BFgiro-a-la-izquierda-o-giro-descolonial-evo-moralesen-bolivia/> Consultado el 31 de marzo de 2010.

Moratinos, Miguel Ángel (2006), «Nuevo Occidente», en Foreign Policy $\mathrm{n}^{\circ} 16$, agosto-septiembre, p. 82.

Navia, Patricio (2009), "No votar votando", en Diario La Tercera, edición electrónica, junio, 2009. <http://blog.latercera.com/ blog/pnavia/entry/no_votar_votando> Consultado el 9 de diciembre de 2009.

Nora, Pierre (1998), «The era of Conmemoration", en Nora, Pierre (dir.), Realms of memory. The Construction of the French past, Vol. 3, Nueva York, Columbia Press, p. 637.

Noya, Javier (2009), La nueva imagen de España en América Latina, Madrid, Tecnos-Real Instituto Elcano, pp. 99-102.

Palacio, Vicente (2009), "El nuevo Hemisferio Occidental», Diario El País, 11 de junio.

Pinto, Julio, «La Construcción Social de la Nación. Chile, 1810-1840», en Revista de Historia Social y de las Mentalidades, Santiago, Año XIII, Vol. 1, 2009, p. 10.

Rodríguez Zapatero, José Luis (2008), «En interés de España. Una política exterior comprometida", en $V^{a}$ Conferencia de Embajadores, MAEC, [08-XI-2008], p. 19.

SALAZAR, Gabriel (2010), «En lo ajeno reina la desgracia", en Diario Las últimas noticias [18-01-2010]. Consultado el 5 de marzo de 2010.

SANchez, Félix (et. al.) (2008), «Brasil. El PT en el gobierno: De la euforia al desencanto", en Chávez, Daniel; César, Rodríguez y Patrick Barret (eds.) (2008), La nueva izquierda en América Latina, Madrid, Libros de la Catarata, p. 104.

Serrano, Sol, (2009), «La promesa de 1810» en Luces y Sombras del Bicentenario, Dvcenti Anniversarivm, $2^{\circ}$ sesión, Bienvenido Bicentenario, Santiago, ENADE, 17 de noviembre. <http://www.icare.cl/ eventos_anteriores_2009/enade/pdfs/ Sol_Serrano.pdf> Consultado el 20 de marzo de 2010

(2003), "¿Hay bicentenario sin nación?», en Diario El Mercurio, 9 de marzo, <http://www.hist.puc.cl/cinfo/ Articulos/serrano3.htm> Consultado 20 de marzo de 2010.

Subercaseaux, Bernardo (2010),»Historia de las ideas y la cultura en Chile e Hispanoamérica. Un enfoque en torno a los Bicentenarios», en Revista Historia del Presente 15, I.

(2008), «Un país que baila en la cuerda floja», en Figueroa, Maximiliano y Manuel Vicuña, El Chile del Bicentenario, Santiago, ediciones Diego Portales, pp. 153-154.

TAPIA, Luis (2008), «Bolivia. La izquierda y los movimientos sociales», en Chávez, Daniel, César Rodríguez y Patrick Barret (eds.), La nueva izquierda en América Latina, Madrid, Libros de la Catarata, p. 307.

Tenorio, Mauricio (2010), Historia y celebración. América y sus centenarios, Barcelona, Tusquets Editores.

Valenzuela, Arturo (2009), «Desafíos de la gobernabilidad democrática en América Latina", Conferencia en Casa de América, Madrid 12 de marzo. 